\title{
A Poem for National Geographic
}

The Wallace Stevens investigation

$\mathrm{X}$ 'ed out his lungs

$\mathrm{Hu}-\mathrm{Huh}-\mathrm{Huh}$

$\mathrm{Cl}$-ck-his whole throat sealed up

The dam busted, it was like Vladimir with a sword His Highlander calves clenched

As if beanbags were sewn in

His tongue sweated

A little rainy-foggy, nice and moist

The definite plasma spun off

Huh-hh-hulp-huh

\section{A Poem for Yellow Silk}

Danish pastry

Squiggled with white

Erin Soma, she called herself

Her day was a sucked egg and I painted its insides 